\title{
PENERAPAN RADIO FREQUENCY IDENTIFICATION PADA SISTEM INFORMASI PERPUSTAKAAN SEBAGAI ALAT BANTU MAHASISWA UNIVERSITAS XYZ
}

\author{
Muryan Awaludin, Gerly Nasukha Pribadi \\ Universitas Dirgantara Marsekal Suryadarma Email: \\ muryanawaludin1@gmail.com,gerly118@gmail.com
}

\begin{abstract}
The library is part of the learning resources that must be possessed by every field of education including universities. Because with the existence of a library it is expected that students can more easily find information or knowledge through a library. With the development of technology makes people think to be able to work more effectively and efficiently. One of them is to simplify activities in the library into a system that can help the process of activities at the university. By utilizing Radio Frequency Identification (RFID) technology, libraries can cut time. So that it can accelerate and simplify existing activities. In this study applying a web-based information system and utilizing RFID technology as a tool to facilitate students and library officers. With this system, it is expected to be able to overcome the various needs of students to search for books and conduct loans and make it easier for officers to circulate books and make reports. From the results of the research that has been done, the writer poured the results of the research into the Application of RFID Technology Information System as Electronic Access at the Aerospace University Marshal Suryadarma Library.
\end{abstract}

Keywords: RFID, Library, Information System

\section{PENDAHULUAN}

Di era digital saat ini, teknologi telah banyak dikembangkan baru-baru ini, banyak bermunculan dan itu dapat mengubah masa depan sains untuk mempengaruhi kehidupan sehari-hari (Ali N.S, \& Alyasseri Z.A.A;2017). Kelahiran paradigma komunikasi baru seperti Internet of Things (IoT) yang memimpikan dunia perangkat yang saling terhubung dan mampu bertukar informasi (J.M. LeonCoca, D.G. Reina, S.L. Toral, F.Barrero, N.Bessis;2013). Teknologi Informasi telah memainkan peran penting dalam mengembangkan beberapa aspek di sektor akademik dan domain seperti pemantauan siswa dan sistem manajemen universitas (Yuru Z, Delong C \& Liping T;2013) (Sunehra D, \& Goud V.S;2016). Oleh karena itu, Memiliki sistem informasi yang andal dan dapat diandalkan sangat penting untuk mendukung pengambilan keputusan, perencanaan dan pelaksanaan operasi (Peter E.D. Love, Jingyang Zhou, Jane Matthews, Harbin Luo;2016).

Baru-baru ini, teknologi kartu pintar digunakan dalam berbagai aplikasi besar di banyak industri. Seperti, pendidikan, Industri perawatan kesehatan, lembaga keuangan, mobil, buku dan peralatan komputer (Patel U.A, \& Swaminarayan Priya R;2014). Karena fitur keamanan pribadinya seperti kontrol akses, kemampuan untuk melakukan beberapa fungsi dan meningkatkan kemampuan itu dapat digunakan sebagai kartu multi-fungsi di lingkungan universitas (Hamed Taherdoost; 2016). Kartu pintar cukup penting dikembangkan dilingkungan universitas, karena dapat membantu mendorong siswa untuk meng- 
ubah efisiensi pembelajaran, meningkatkan nilai pembelajaran dan akhirnya meningkatkan tingkat pendidikan (Sayanekar P, Rajiwate A, Qazi L, \& Kulkarni A.;2016) (Noor SAM, Zaini N, Latip MFA \& Hamzah N;2015).

Universitas XYZ memiliki akses sarana dan prasarana untuk mendukung kegiatan akademik dan non akademik mahasiswa di lingkungan Universitas. Kartu Tanda Mahasiswa (KTM) adalah salah satu kunci utama mahasiswa untuk mengakses berbagai fasilitas yang disediakan universitas. Selain itu KTM Universitas XYZ digunakan sebagai tanda pengenal atau identitas dari pemegang kartu. Kartu ini memuat data diri pada pemegang kartunya seperti nama, Nomer Induk Mahasiswa (NIM), jurusan, tahun masuk, dll. Namun, dalam beberapa akses fasilitas yang disediakan masih menggunakan kartu yang berbeda seperti pada akses ruang perpustakaan (Adhiarna et al, 2013). Permasalahan ini terjadi dalam penggunaan ruangan ini, yaitu mahasiswa mengisi daftar tamu terlebih dahulu sebelum masuk ruang perpustakaan, tujuan langkah ini untuk mendata setiap pengunjung/ tamu yang ada dalam perpustakaan, tujuan lainnya adalah untuk menjaga keamanan buku-buku di perpustakaan dari tindak pencurian (Akbar et al, 2017). Selain itu terdapat permasalahan lainnya, untuk peminjaman buku tertentu, seperti skripsi, tugas akhir dan lain-lain mahasiswa diwajibkan mendaftarkan diri sebagai anggota terlebih dahulu pada petugas perpustakaan (Anthadi et al, 2013), dengan menyerahkan KTM pada petugas perpustakaan, data yang tercantum di KTM mahasiswa, akan ditulis ulang pada kartu perpustakaan. Proses ini bertujuan untuk mengidentifikasi mahasiswa dalam peminjaman buku (Andersons \& Ritter (2015). Dalam prosedurnya, mahasiswa harus menunggu beberapa saat untuk mendapatkan kartu perpustakaan dan mahasiswa harus membayar uang administrasi sebesar Rp.10.000,- (Sepuluh ribu rupiah), kemu- dian setelah mahasiswa sudah menyelesaikan administrasi, kartu mulai dicetak, setelah kartu selesai di cetak kartu di serahkan pada mahasiswa (Arif et al, 2003). Mahasiswa yang baru mendaftar sebagai anggota dapat meminjam buku-buku yang disediakan perpustakaan (Beal, 2015). Maka permasalahan yang dijelaskan diatas, kegiatan mahasiswa yang dilakukan di perpustakaan Universitas XYZ belum sepenuhnya menghemat waktu (Giunio et al, 2013). Dikarenakan belum adanya suatu sistem untuk mengidentifikasi mahasiswa Universitas XYZ, maka kegiatan yang dilakukan untuk mengakses ruang perpustakaan, mahasiswa harus memiliki dua kartu identitas, satu dipergunakan untuk identitas diri dan satu untuk identitas anggota di perpustakaan. Dengan adanya hal ini maka KTM yang saat ini dipergunakan oleh setiap individu mahasiswa, belum dapat diintertegrasikan pada layanan opsinal perpustakaan. Salah satu untuk menyelesaikan permasalahan tersebut adalah, perlunya membangun sistem informasi yang baik dan mampu menyerderhanakan sistem manajemen perpustakaan, yaitu dengan kartu pintar berteknologi Radio Frequency IDentification (RFID), hal ini bertujuan untuk mempermudah akses pada layanan opsional perpustakaan di universitas dan mempermudah mahasiswa dalam melakukan kegiatan di ruang perpustakaan hanya dengan satu kartu, serta membantu petugas perpustakaan dalam pengawasan kegiatan yang berlangsung di perpustakaan.

Sejumlah besar pengembangan kartu pintar telah terjadi di universitas selama beberapa tahun terakhir. Kartu pintar dapat dirancang untuk universitas yang berfungsi sebagai staf atau identifikasi mahasiswa yang berisi foto pemegang kartu serta nama, tanda tangan, tanggal lahir dan nomor induk mahasiswa (Constance et al;2017). Kartu pintar juga memungkinkan staf atau siswa untuk memiliki akses ke fasilitas kampus (Cui et al, 2016). Kartu pintar dapat digunakan oleh staf atau siswa ketika 
meminjam buku dari universitas, kemanan dalam pengawasan parkir, dompet elektronik dan presensi mahasiswa. (Halawani dan Mohandes;2003) (Salih et al, 2016) (Drum et al, 2017). Hal ini menunjukan bahwa kartu pintar dapat dimanfaatkan sebagai alat identifikasi setiap individu mahasiswa serta menjalankan fungsi sebagai staff layanan opsional di kampus yang sebelumnya diminta untuk menggunakan kartu terpisah untuk ketentuan tersebut, seperti uang tunai, kartu perpustakaan dan Identitas Siswa (Rankl dan Effing;2003; Guthery dan Cronin;2004) (Firmansyah, 2014).

RFID merupakan teknologi otomasi yang dapat digunakan untuk mengidentifikasi objek (Husemann, 2001) (Hu et al, 2016) dan telah menarik banyak perhatian selama beberapa tahun terakhir dan digunakan sebagai alat identifikasi yang efektif (Zudor, 2016) (Kumar, Jay, dan Amit Kumar;2016). RFID saat ini dianggap sebagai salah satu teknologi autoidentifikasi (Jia et al, 2012) dan capture yang paling menjanjikan, disisi lain banyak literatur telah membahasnya sebagai salah satu dari enam belas teknologi kunci dalam dekade mendatang (Silberglitt, Anton, Howell dan Wong;2006) (Joshi et al, 2015). Meskipun popularitasnya luar biasa (Jyothi et al, 2016), kartu berteknologi RFID ini terdapat beberapa kelemahan lainnya. Seperti akomodasi pengembangan teknologi yang cukup mahal dikarenakan teknologi RFID (Louw \& Wolker, 2018) ini masih tergolong teknologi yang masih baru, biaya pemeliharaan integritas sistem data yang tidak murah, serta perombakan manajemen sistem lama menjadi yang baru (Oluwatosin, 2014). Maka tujuan dalam penelitian ini adalah mempermudah mahasiswa dalam mengakses layanan opsional universitas (Rachmat \& Hutabarat, 2014) khususnya fasilitas perpustakaan, dengan menyerderhanakan sistem menejemen perpustakaan, dengan cara menghubungkan beberapa tugas secara organic (Satoglu,
2013), hal ini akan memperkuat pembagian sumber daya internal, mengurangi duplikasi konstruksi, mengurangi pemborosan sumber daya yang ada dan layanan perpustakaan universitas yang dapat di akses dengan mudah (Waytz \& Epley, 2012).

\section{PENELITIAN TERKAIT}

Sebuah penelitian tentang pemanfaatan teknologi smart-card pada kartu mahasiswa yang digunakan untuk mencapai semua manajemen kampus yang dilakukan oleh (Zhang Weijun et al;2012). Penelitian diakukan untuk menyederhanakan sistem manajemen dengan mengunakaan teknologi smart-card pada kartu mahasiswa dan membangun pararel jaringan smart-card. Hasil dari penelitian ini membuktikan bahwa mengadopsi teknologi smart-card sebagai kartu multi-fungsi mahasiswa sangat membantu sistem manajemen di universitas.

Akses sarana maupun prasarana di universitas yang begitu banyak membuat mahasiswa memiliki beberapa kartu akses yang berbeda, seperti, kartu konsumsi makanan kafetaria (Widianto et al, 2017), kartu mencuci pakaian, kartu akses ruang baca elektronik, kartu telepon umum dan kartu perpustakaan. Hal ini membuat manajemen kampus yang mengolahnya memiliki sistem manajemen yang berbeda pada setiap fasilitas sarana dan prasarana yang dimiliki univeritas. sehingga setiap akses yang ada di universitas memiliki kartu akses yang berbeda (Williamson, 2013). Maka dari itu penelitian ini bertujuan untuk menyederhakan sistem manajemen di universitas. Dengan mengadopsi teknologi smart-card sebagai kartu multi-fungsi pada kartu tanda mahasiswa, serta membangun topologi jaringan yang mampu mengintegrasikan setiap fasilitas yang di sediakan (Zahendi, 2008). Topologi bus dipilih sebab, seluruh client dan server dihubungkan pada satu jaringan. Sehingga komputer lain dapat dengan mudah 
dihubungkan satu sama lain (Sigmund \& Torquato;1999).

Penelitian ini didasarkan pada penilaian konversi ke RFID pada 2016 di satu akademi dan perpustakaan di universitas Lulea (Denmark). Pada penelitian ini menerapkan RFID tag pasif yang disertakan dalam buku. Frekuensi yang digunakan untuk perpustakaan $125 \mathrm{KHz}$. Di perpustakaan, tag dapat membaca sinyal dari jarak dua hingga tiga meter. Buku-buku dipinjamkan dengan menempatkan mereka dekat dengan pembaca, yang segera mendaftar buku, terlepas dari lokasi tag. Operasi dapat diprakarsai oleh mahasiswa, yang mengurangi tenaga kerja di perpustakaan untuk tujuan lain yang bermanfaat. Pembaca saling berhubungan dengan sistem perpustakaan melalui perangkat lunak khusus dan menginstruksikan sistem perpustakaan tentang status buku/ peminjam buku/mengatur alarm. Pendekatan lain adalah tag RFID dalam buku-buku ini berisi informasi ID tentang item seperti: negara, perpustakaan dan kode lain yang menunjukkan item, serta mengintegrasikan dengan kartu tanda mahasiswa.

Dalam perpustakaan di Lulea tersedia puluhan ribu buku, seringkali membuat petugas harus selalu mengawasi dan memantau kegiatan yang dilakukan di perpustakaan, seperti pencatatan keluar masuknya mahasiswa, pencatatan buku yang dipinjam mahasiswa dan pengembalian buku di perpustakaan belum sepenuhnya efektif. Sehingga membuat permasalahan terhadap kegiatan yang dilakukan perpustakaan universitas, maka penelitian ini dilakukan untuk mempermudah petugas dalam memantau buku-buku yang ada di univeritas Lulea (Denmark), sistem ini mampu membuat buku-buku tetap aman, mengurangi tindak pencurian pada buku-buku yang tersedia, serta mampu memantau kegiatan pinjam meminjam di perpustakaan.
Penelitian ini memanfaatkan sistem keamanan dari teknologi indentifikasi berbasis objek yaitu RFID dengan membahas sistem perpustakaan khusus untuk buku-buku yang dapat diimplementasikan di lingkungan perguruan tinggi dengan mengintegrasikan teknologi kartu RFID yang harus dimiliki oleh setiap buku-buku yang tersedia. Hasil dari penelitian ini adalah sistem perpustakaan untuk bukubuku yang tersedia di Universitas Oslo (Denmark). Kesimpulan yang didapatkan bahwa sistem ini dapat meningkatkan keamanan buku-buku yang tersedia, serta dapat meningkatkan efektifitas dan efisiensi dalam perpustakaan, dalam perihal operasional di perpustakaan.

Kegiatan yang dilakukan pada perpustakaan yang disediakan universitas membuat petugas perpustakaan kurang dapat memantau keluar masuknya mahasiswa dan pengunjung lainnya yang ada di perpustakaan universitas, mengingat selalu ada mahasiswa ataupun pengunjung yang terus berganti setiap tahunnya, maka permasalahan terjadi pada pemantauan keluar masuknya buku yang tersedia di universitas, dikarenakan belum adanya penandaan khusus pada setiap buku, mengakibatkan tindak pencurian dan kehilangan terhadap buku-buku perpustakaan masih memiliki peluang yang besar. Maka pada penelitian ini membuat suatu sistem penandaan khusus pada setiap bukubuku yang tersedia di universitas Oslo (Denmark) yang dapat dipantau 7x24 jam, serta membantu tugas dari petugas perpustakaan dalam pemantauan keluar masuknya mahasiswa dan pemantauan tindak kejahatan pencurian buku.

\section{METODOLOGI PENELITIAN}

Sistem yang diusulkan

Berdasarkan hasil evaluasi sistem yang berjalan, sistem yang diusulkan adalah perlu adanya pengembangan KTM (Kartu Tanda Mahasiswa) di Sistem Informasi 
Perpustakaan Universitas XYZ dengan memanfaatkan teknologi Radio Frequency Identification (RFID), sebagai alat bantu perpustakaan untuk proses sirkulasi pada perpustakaan.

Pada dasarnya prosedur yang dilakukan hampir sama jika pengelola perpustakaan menggunakan sistem lama untuk setiap proses yang berjalan di perpustakaan. Dengan adanya teknologi RFID di perpustakaan proses sirkulasi akan lebih cepat, mempermudah akses mahasiswa di perpustakaan meggunakan 1 (satu) kartu, meningkatkan pengawasan terhadap pengunjung perpustakaan, dan meningkatkan pengawasan terhadap buku yang tersedia di perpustakaan.

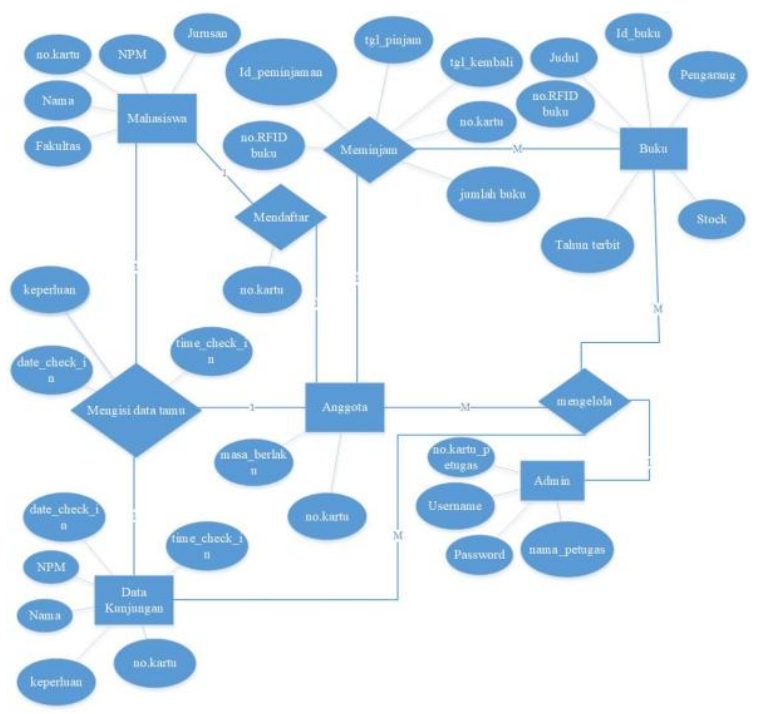

Gambar Rancangan Entity Relationship Diagram (ERD) pada sistem informasi perpustakaan universitas XYZ

\section{HASIL DAN PEMBAHASAN}

Setelah aplikasi selesai dibuat maka dilakukanlah dua tahapan uji coba yaitu uji coba kartu dan program aplikasi perpustakaan dengan teknik wawancara kepada 5 mahasiswa dan 1 petugas perpustakaan, serta uji coba black box. Uji coba program dilakukan guna mengetahui apakah aplikasi perpustakaan ini sudah sesuai dengan kebutuhan perpustakaan Universitas XYZ.

Cara pengujian dilakukan dengan 10 kartu RFID. Ke-10 kartu tersubut dibagi mejadi 2, yaitu 5 kartu untuk mahasiswa, 4 untuk buku diperpustakaan dan 1 untuk pustakawan. Pengujian juga dilakukan dengan melihatkan program yang dibuat dan masing-masing mahasiswa di berikan 1 kartu RFID yang berisi data diri mahasiswa tersebut sebagai tanda pengenal mahasiswa atau KTM dan sebagai alat inputan pada Aplikasi perpustakaan, disertai dengan wawancara kepada 5 mahasiswa dan 1 orang petugas perpustakaan. Pertanyaanpertanyaan ini terkait pada tampilan aplikasi, fungsi-fungsi pada aplikasi dan kemudahan pengguna dalam pengoprasiannya. Hasil wawancara secara lengkap dapat dilihat pada lampiran adapun di bawah ini merupakan tabel perbandingan sistem lama dan sistem yang diusulkan, serta hasil uji coba black box yang dilakukan:

a. Perbandingan antara sistem tradisional dan sistem yang diusulkan :

Tabel Perbandingan antara sistem tradisional dan sistem yang diusulkan

\begin{tabular}{|l|c|c|}
\hline Parameter & $\begin{array}{c}\text { Sistem yang } \\
\text { berjalan }\end{array}$ & $\begin{array}{c}\text { Sistem yang } \\
\text { diusulkan }\end{array}$ \\
\hline $\begin{array}{l}\text { Konsumsi } \\
\text { Waktu }\end{array}$ & \pm 5 menit & \pm 1 menit \\
\hline Kecepatan & $\begin{array}{c}\text { Lambat } \\
\text { (Manusia) }\end{array}$ & $\begin{array}{c}\text { Cepat } \\
\text { (komputer) }\end{array}$ \\
\hline $\begin{array}{l}\text { Pencatatan } \\
\text { Dokumen }\end{array}$ & $\begin{array}{c}\text { Menggunakan } \\
\text { media } \\
\text { Kertas }\end{array}$ & $\begin{array}{c}\text { Menggunak } \\
\text { an 1 } \\
\text { elektronik } \\
\text { record }\end{array}$ \\
\hline $\begin{array}{l}\text { Akurasi } \\
\text { data }\end{array}$ & kurang & Tepat \\
\hline $\begin{array}{l}\text { Kemudahan } \\
\text { Pengguna }\end{array}$ & Tidak & Ya \\
\hline
\end{tabular}


b. Uji coba kartu RFID pada mahasiswa

Tabel Uji coba kartu RFID pada mahasiswa

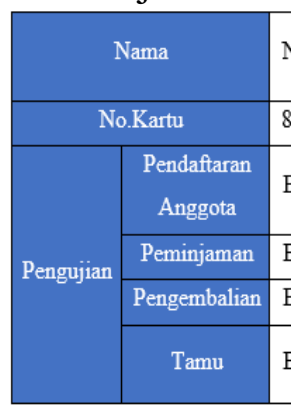

\begin{tabular}{|c|c|c|c|c|}
\hline Naharoh & $\begin{array}{c}\text { Hangga } \\
\text { B }\end{array}$ & Divo & Imam $T$ & $\begin{array}{c}\text { Bayu } \\
\text { Wisnoe }\end{array}$ \\
\hline 8808495 & 8808544 & 8807397 & 8810104 & 8807574 \\
\hline Berhasil & Berhasil & Berhasil & Berhasil & Berhasil \\
\hline Berhasil & Berhasil & Berhasil & Berhasil & Berhasil \\
\hline Berhasil & Berhasil & Berhasil & Berhasil & Berhasil \\
\hline Berhasil & Berhasil & Berhasil & Berhasil & Berhasil \\
\hline
\end{tabular}

c. Uji coba RFID pada buku:

Tabel Uji coba RFID pada buku

\begin{tabular}{|c|c|c|c|c|c|c|c|}
\hline \multirow{2}{*}{ No } & \multirow{2}{*}{$\begin{array}{c}\text { No.RFI } \\
\mathrm{D}\end{array}$} & \multirow{2}{*}{ Judul } & \multicolumn{5}{|c|}{ Pengujian } \\
\cline { 5 - 8 } & 8807849 & $\begin{array}{c}\text { Input } \\
\text { Ilmu } \\
\text { Komputer }\end{array}$ & Berhasil & Berhasil & Berhasil & Berhasil & Berhasil \\
\hline 2 & 8807894 & $\begin{array}{c}\text { Jurnal } \\
\text { ICAO }\end{array}$ & Berhasil & Berhasil & Berhasil & Berhasil & Berhasil \\
\hline 3 & 8807897 & $\begin{array}{c}\text { Jurnal } \\
\text { IImiah } \\
\text { Widya }\end{array}$ & Berhasil & Berhasil & Berhasil & Berhasil & Berhasil \\
\hline 4 & 8810071 & $\begin{array}{c}\text { Jurnal } \\
\text { Sistem } \\
\text { Informasi }\end{array}$ & Berhasil & Berhasil & Berhasil & Berhasil & Berhasil \\
\hline
\end{tabular}

d. Uji coba tag media penghalang Buku dengan tebal $3,6 \mathrm{~cm}$.

Tabel Uji coba tag media penghalang Buku dengan tebal 3,6 cm

\begin{tabular}{|c|c|c|}
\hline Pengujian & $\begin{array}{c}\text { Jarak } \\
\text { maximum } \\
\text { baca }(\mathrm{cm})\end{array}$ & $\begin{array}{c}\text { Objek } \\
\text { Penghalang }\end{array}$ \\
\hline 1 & 6 & \multirow{10}{*}{$\begin{array}{l}\text { Buku dengan } \\
\text { tebal } 3,6 \mathrm{~cm}\end{array}$} \\
\hline 2 & 5,7 & \\
\hline 3 & 6 & \\
\hline 4 & 6 & \\
\hline 5 & 6 & \\
\hline 6 & 5,7 & \\
\hline 7 & 5,9 & \\
\hline 8 & 6 & \\
\hline 9 & 6 & \\
\hline 10 & 6 & \\
\hline
\end{tabular}

e. Uji coba tag media penghalang Kayu dengan tebal $4 \mathrm{~cm}$.

Tabel Uji coba tag media penghalang Buku dengan tebal 3,6 cm

\begin{tabular}{|c|c|c|}
\hline Pengujian & $\begin{array}{c}\text { Jarak } \\
\text { maximum } \\
\text { baca }(\mathrm{cm})\end{array}$ & $\begin{array}{c}\text { Objek } \\
\text { Penghalang }\end{array}$ \\
\hline 1 & 6 & \multirow{10}{*}{$\begin{array}{c}\text { Kayu dengan } \\
\text { tebal } 4 \mathrm{~cm}\end{array}$} \\
\hline 2 & 5,7 & \\
\hline 3 & 5,7 & \\
\hline 4 & 6 & \\
\hline 5 & 6 & \\
\hline 6 & 5,2 & \\
\hline 7 & 5,9 & \\
\hline 8 & 6 & \\
\hline 9 & 6 & \\
\hline 10 & 6 & \\
\hline
\end{tabular}

f. Uji coba tag media penghalang plat nomer dengan tebal $1 \mathrm{~mm}$.

Tabel Uji coba tag media penghalang Buku dengan tebal 3,6 cm

\begin{tabular}{|c|c|c|}
\hline Pengujian & $\begin{array}{c}\text { Jarak } \\
\text { maximum } \\
\text { baca }(\mathrm{cm}) \\
\end{array}$ & $\begin{array}{c}\text { Objek } \\
\text { Penghalang }\end{array}$ \\
\hline 1 & 6 & \multirow{10}{*}{$\begin{array}{c}\text { Plat nomer } \\
\text { dengan tebal } 1 \\
\mathrm{~mm}\end{array}$} \\
\hline 2 & 5,7 & \\
\hline 3 & 5,7 & \\
\hline 4 & 5 & \\
\hline 5 & 6 & \\
\hline 6 & 5,7 & \\
\hline 7 & 5,5 & \\
\hline 8 & 6 & \\
\hline 9 & 6 & \\
\hline 10 & 6 & \\
\hline
\end{tabular}




\section{KESIMPULAN}

Dari hasil wawancara yang dilakukan didapat bahwa mahasiswa dan petugas perpustakaan mendukung teknologi RFID dikembangkan karena dapat membantu perpustakaan dalam kegiatan yang berlangsung di ruang perpustakaa. Uji coba kompatibilitas diujikan pada 3 penghalang dengan ukuran dan tebal yang berbeda sehingga dapat dilihat perbedaan dari segi kemampuan RFID dalam membaca data. Dimana pada pengujian ini didapatkan hasil bahwa teknologi RFID ini dapat berjalan pada semua penghalang dengan maximal jarak antara RFID tag dengan RFID reader adalah 5-6 cm.

\section{REFERENSI}

Adhiarna, N., Hwang, Y. M., Park, M. J., \& Rho, J. J. (2013). An integrated framework for RFID adoption and diffusion with a stage-scale-scope cubicle model: A case of Indonesia. International Journal of Information Management, 33(2), 378-389.

Akbar, M., \& Effendy, I. (2017). Implementasi Aplikasi Kehadiran Perkuliahan Dikelas Menggunakan Pembaca RFID Pada e-KTP. Informatika, xx(xx), 31-35.

Anthadi, A., Amin, W., \& Darjat. (2013). Pemanfaatan Teknologi Rfid Untuk Sistem Multi Akses Mahasiswa. Transmisi, 15 Nomor 1, 8-12.

Andersons, A., \& Ritter, S. (2015). Advanced RFID applications for sports events management: The case of SPORTident in Latvia. Procedia Computer Science, 43(C), 78-85.

Arif, O. I., Seminar, M., Membangun, S., \& Perpustakaan, J. (2003). Konsep dan Perencanaan dalam Automasi Perpustakaan. Konsep Dan Perencanaan Dalam Automasi Perpustakaan.

Beal, V. (2015). Client-Server Architecture. Webopedia

Cej, V., Giunio, K., \& Silić, T. (2013). RFID technology in Zagreb City libraries . Vjesnik Bibliotekara Hrvatske.

Constance, E. (2017). The Internet of Things: preparing for the revolution. Journal of Cyber Policy (Vol. 2).

Cui, B., Wang, Z., Zhao, B., \& Chen, X. (2016). Design and analysis of secure mechanisms based on tripartite credibility for RFID systems.

D., H., Salih, N., Al, A., Al-Sadawi, B., \& Alsharqi, H. (2018). Attendance and Information System using RFID and Web-Based Application for Academic Sector. International Journal of Advanced Computer Science and Applications, 9(1), 266274. 
Druml, N., Schilling, J., Pachler, W., Roitner, B., Ruprechter, T., Bock, H., \& Holweg, G. (2017). Secured miniaturized system-in-package contactless and passive authentication devices featuring NFC. Microprocessors and Microsystems, 53, 120 129.

Duroc, Y., \& Tedjini, S. (2018). La RFID : une technologie clé au service de l'humanité. Comptes Rendus Physique, 19(1-2), 64-71.

Firmansyah Agustian. (2014). Adobe Dreamweaver. Jurnal Desain web. https://doi.org/2016-06-23

Hameed, S., Saquib, S. M. T., Hassan, M. ul, \& Junejo, F. (2015). Radio Frequency Identification (RFID) Based Attendance \&amp; Assessment System with Wireless Database Records. Procedia - Social and Behavioral Sciences, 195, 2889-2895.

Husemann, D. (2001). Standards in the smart card world. Computer Networks, 36(4), 473487.

Hu, Q., Dinca, L. M., Yang, A., \& Hancke, G. (2016). Practical limitation of co-operative RFID jamming methods in environments without accurate signal synchronization. Computer Networks, 105, 224-236.

Ilie-Zudor, E., Kemény, Z., Van Blommestein, F., Monostori, L., \& Van Der Meulen, A. (2011). A survey of applications and requirements of unique identification systems and RFID techniques. Computers in Industry, 62(3), 227-252.

Jia, X., Feng, Q., Fan, T., \& Lei, Q. (2012). RFID technology and its applications in Internet of Things (IoT). In 2012 2nd International Conference on Consumer Electronics, Communications and Networks (CECNet).

Joshi, Y., Gharate, P., Ahire, C., Alai, N., \& Sonavane, S. (2016). Smart book management system using RFID and OCR. In International Conference on Energy Systems and Applications, ICESA 2015.

Jyothi, S. N., \& Vardhan, K. V. (2016). Design and implementation of real time security surveillance system using IoT. In Proceedings of the International Conference on Communication and Electronics Systems, ICCES 2016.

Louw, L., \& Walker, M. (2018). Design and implementation of a low cost RFID track and trace system in a learning factory. Procedia Manufacturing, 23(2017), 255-260.

Oluwatosin, H. S. (2014). Client-Server Model. IOSR Journal of Computer Engineering.

Rachmat, H. H., \& Hutabarat, G. A. (2014). Pemanfaatan Sistem RFID sebagai Pembatas Akses Ruangan. Jurnal ELKOMIKA Institut Teknologi Nasional Bandung.

Satoglu, S. I., Ustundag, A., \& Kilinc, M. S. (2013). Value of RFID in library management 
system. In The Value of RFID: Benefits Vs. Costs.

Waytz, A., \& Epley, N. (2012). Social connection enables dehumanization. Journal of Experimental Social Psychology.

Weijun, Z., \& Changqing, C. (2012). To achive a Campus Interchangeable Card Based on RFID Technology. Energy Procedia.

Widianto, E. D., Wijaya, H. M., \& Windasari, I. P. (2017). Sistem Parkir Berbasis RFID dan Pengenalan Citra Pelat Nomor Kendaraan. Jurnal Teknologi Dan Sistem Komputer, 5(3), 115.

Williamson, “Avery, Tsay, L.-S., Kateeb, I. A., \& Burton”, L. (2013). "Solutions for RFID Smart Tagged Card Security Vulnerabilities.” AASRI Procedia, 4, 282-287.

Zahedi, A. (2008). MASTER' S THESIS Intention to Adopt Smart Cards Case of Application in Universities Intention to Adopt Smart Cards; Case of Application Supervisors : 
